\title{
Visual impairment amongst adult diabetics attending a tertiary outpatient clinic
}

\author{
Seth Y. Lartey ${ }^{1,2}$ and Amos K. Aikins ${ }^{2}$
}

Ghana Med J 2018; 52(2): 84-87 doi: http://dx.doi.org/10.4314/gmj.v52i2.4

\begin{abstract}
${ }^{1}$ College of Health Sciences School of Medical Sciences. Eye Ear Nose and Throat Department, Kwame Nkrumah University of Science and Technology, Kumasi, Ghana. ${ }^{2}$ Komfo Anokye Teaching Hospital, Eye Clinic. Kumasi, Ghana.
\end{abstract}

\author{
Corresponding author: Dr Seth Lartey \\ Conflict of interest: None declared
}

E-mail: sylartey.chs@knust.edu.gh

\section{SUMMARY}

Background: To determine the prevalence of diabetic retinopathy maculopathy and cataract amongst diabetics and the prevalence of visual impairment amongst diabetics attending the Komfo Anokye Teaching Hospital eye unit. There are no current data in the study area on the prevalence of visual impairment and blindness amongst diabetics. This data is required in planning for screening and prevention of blindness due to diabetics.

Methods: This was a hospital based cross sectional study. Subjects were diabetic patients attending the diabetic clinic. Simple random sampling was used. Demographic was taken. Visual acuity and refraction was done. Slit lamp examination was used to identify cataract. Maculopathy and retinopathy was determined using a 90D Volk lens and an indirect ophthalmoscope.

Results: Non -insulin dependent diabetics constituted $97.1 \%$ whilst $2.9 \%$ were insulin dependent diabetics. The prevalence of the outcomes measures was: Cataract $(23.7 \%)$ mild and moderate retinopathy $(13.7 \%)$ severe proliferative retinopathy (1.8\%) maculopathy (6.8\%). Prevalence of low vision and blindness was $18.4 \%$. Amongst diabetics $59.1 \%$ had no previous eye evaluation. Impaired vision due to cataract was $24.0 \%$ representing a $40 \%$ decline in a decade.

Conclusion: The prevalence of visual impairment was high at $18.4 \%$. The reduction in impaired vision due to cataract over a decade is suggestive of either an improved cataract surgical rate or improved diabetic care or both. Majority of the diabetic patients $59.1 \%$ had not received prior ocular evaluation. There is an urgent need to have a screening program in this area

Funding: None

Keywords: Diabetics, retinopathy, maculopathy, visual impairment, blindness

\section{INTRODUCTION}

Loss of vision is one of the many long-term complications of diabetes mellitus. Globally, diabetes is one of the leading causes of blindness amongst the working population. In 2011 the total number of people with diabetes was estimated to be 366 million globally. This is estimated to rise to 552 million by 2030 as a result of rapid demographic transition due to urbanization, lifestyle changes and an ageing population. Nearly $80 \%$ of this number is said to be in middle and lower income countries. ${ }^{1}$ Between 2010 and 2030, there will be a projected $69 \%$ increase in the numbers of adults with diabetes in developing countries. ${ }^{2}$ Met-analysis of the overall global prevalence of Diabetic Retinopathy (DR) from a total of 35 studies (1980-2008) was $34.6 \%$ for any Diabetic Retinopathy, $6.96 \%$ for proliferative Diabetic Retinopathy, $6.81 \%$ for Diabetic Macular Oedema, and $10.2 \%$ for vision-threatening Diabetic Retinopathy. ${ }^{3}$
An analysis by Burgess et al of sixty-two studies from 21 African countries showed prevalence of diabetic retinopathy ranged from 30.2 to $31.6 \%$, proliferative diabetic retinopathy 0.9 to $1.3 \%$, and any maculopathy 1.2 to $4.5 \%$ in population-based studies. In clinic-based surveys, the reported prevalence ranged from 7.0 to $62.4 \%$, proliferative diabetic retinopathy 0 to $6.9 \%$, and any maculopathy 1.2 to $31.1 \%{ }^{4}$ In Ghana and Nigeria the prevalence of all diabetic retinopathy was $17.7 \% .^{5}$

Loss of vision in diabetics is due mainly to retinopathy including maculopathy. Retinopathy progresses from a latent asymptomatic stage to a visually symptomatic stage. Apart from diabetic retinopathy, cataract due to the osmotic changes in uncontrolled diabetics is common. Many of these diabetics will end up being legally blind. 
Legal blindness (best corrected visual acuity of $6 / 60$ or worse in the best eye) is found to be twenty-five times more common in the diabetic population than in those without the disease. ${ }^{6,7}$

Therefore, early and regular screening of all diabetic patients is required to prevent blindness in an already disabling disease. The objective of this study was to determine the prevalence of retinopathy and cataract and to determine the prevalence of visual impairment and legal blindness among diabetic patients attending the Out-Patient Department (OPD) clinic at a Teaching Hospital in the northern sector of Ghana. There are no data existing in this area on the prevalence of visual impairment and legal blindness from diabetics. There is no formal screening program in place in this region for identifying diabetics at risk of blindness. The data will help in the planning for a screening program for diabetic retinopathy and the prevention of blindness due to diabetics.

\section{METHODS}

This is a hospital based cross sectional study involving the adult population of diabetics over a period of three months in the year 2012. The study sites were the Diabetic Center and the Eye Department of a tertiary teaching hospital in the Ashanti region of Ghana. The study participants were patients with confirmed diagnosis of diabetes who attend the diabetic clinic. Patients were selected by simple random sampling (SRS) technique. Using a $25 \%$ probability of being selected and computer generated random numbers. An informed written consent was obtained from each patient. Ethical clearance was sought from the Committee on Human Research, Publications and Ethics, Kwame Nkrumah University of Science and Technology, School of Medical Sciences and Research and Development Unit of Komfo Anokye Teaching Hospital.

The inclusion criteria were confirmed diagnosis of diabetes and patients 18 years and above. The exclusion criteria were patients with gestational diabetes, sickle cell disease, hypertensive and coexisting ocular pathology apart from cataract. Any type of visible lens opacities unilateral or bilateral, was noted by the same examiner. Coexisting ocular morbidity with likely secondary cataract were excluded.

Using a structured questionnaire, data on age, gender, profession, duration of diabetes was obtained. Type of diabetes and treatment type were also obtained from the record of the participants. The visual acuity and pin hole testing with Snellen acuity chart was done. Refraction was done. The anterior segment of the eyes was examined with a slit lamp bio-microscope.
The pupils were then dilated with topical $2 \%$ tropicamide and $2.5 \%$ phenylephrine and fundus examination was done with a 90D Volk lens on a slit lamp, and a Heine indirect ophthalmoscope with 20D Volk lens by the same person. Retinopathy and maculopathy were then determined and graded using the early treatment diabetic retinopathy study (EDTRS) protocol. Participants found to have proliferative retinopathy and/or macular oedema were offered laser treatment or anti Vascular Endothelial Growth Factor injection or both.

\section{Data analysis}

Rates and means were determined and a confidence interval of $95 \%$ was used. The results of prevalence of cataract from this study was then compared with a similar study by Rotimi et al in the same study area and study site a decade ago with similar population to determine the change in prevalence of cataract amongst diabetics in the area in 10 years. In this study, when both eyes had retinopathy, data from the eye with the worse retinopathy was used for the analysis. The eye with the better visual acuity after best corrected vision was used for the analysis of visual acuities. Low vision was defined as visual acuity of less than or equal to $6 / 18$ in the better eye after best corrected vision. Blindness was defined using the legal blindness criteria of visual acuity of less than $6 / 60$ in the better eye after best corrected vision.

\section{RESULTS}

A total of 208 patients participated in the study The mean age $( \pm \mathrm{SD})$ was $57.5 \pm 13$ years. There were more females $(70.7 \%)$ than males. More than half of the participants $(59.1 \%)$ had not been examined by an ophthalmologist ever since they were diagnosed with diabetes mellitus. Of those whose eyes have been examined before, $83.5 \%$ of them had their eyes examined within the last 5 years ago $2.4 \%$ had not been examined. (Table 1).

\begin{tabular}{|c|c|c|}
\hline \multirow{2}{*}{$\begin{array}{l}\mathrm{N}=208 \\
\text { Age(years) }\end{array}$} & Frequency & Percent (\%) \\
\hline & \multicolumn{2}{|c|}{$\operatorname{Mean}(S D)=57.5(13.0)$} \\
\hline \multicolumn{3}{|l|}{ Age category (years) } \\
\hline $19-38$ & 17 & 8.2 \\
\hline $39-58$ & 94 & 45.5 \\
\hline $59-78$ & 83 & 39.9 \\
\hline$>78$ & 14 & 6.7 \\
\hline \multicolumn{3}{|l|}{ Gender } \\
\hline Male & 61 & 29.3 \\
\hline Female & 147 & 70.7 \\
\hline Yes & 85 & 40.9 \\
\hline No & 123 & 59.1 \\
\hline \multicolumn{3}{|c|}{ Last time eyes examined, $N=85$} \\
\hline Less than 5 years & 71 & 83.5 \\
\hline $5-10$ years & 12 & 14.1 \\
\hline More than 10 years & 2 & 2.4 \\
\hline
\end{tabular}


There was $12.6 \%$ of the patients with low vision and $5.8 \%$ were legally blind (Table 2 ).

Table 2 Visual Acuity of the best corrected eye

\begin{tabular}{|l|cc}
$\begin{array}{l}\text { Left/Right Visual } \\
\text { Acuity, } \mathbf{N}=\mathbf{2 0 8}\end{array}$ & Frequency & Percentage \\
\hline $6 / 4$ & 40 & 19.2 \\
$6 / 5$ & 34 & 16.4 \\
$6 / 6$ & 71 & 34.1 \\
$6 / 9$ & 31 & 14.9 \\
$6 / 12$ & 6 & 2.9 \\
$6 / 18$ & 8 & 3.9 \\
$6 / 24$ & 4 & 1.9 \\
$6 / 36$ & 2 & 1.0 \\
$6 / 60$ & 7 & 3.4 \\
CF & 3 & 1.4 \\
HM & 2 & 1.0 \\
\hline
\end{tabular}

Of the eyes examined $23.7 \%$ had cataracts (Table 3), Prevalence of any retinopathy was $15.5 \%$ and prevalence of maculopathy was $6.8 \%$ (Table 4). Impaired vision due to cataract was $24 \%$. Compared to a previous study in the same area by Rotimi et al in 2003 (40\%), impaired vision due to cataract had reduced by $40 \%$ in a decade. ${ }^{5}$

Table 3 Distribution of lens characteristics

\begin{tabular}{l|cc|}
\hline Factor, $\mathbf{N}=\mathbf{4 1 2}$ & Frequency & Percentage (\%) \\
Lens & 304 & 73.8 \\
Clear & 99 & 24.0 \\
Cataract & 9 & 2.2 \\
Pseudophakia &
\end{tabular}

Table 4 Prevalence of diabetic retinopathy and maculopathy

\begin{tabular}{|c|c|c|}
\hline $\begin{array}{l}\text { Prevalence of Retinopathy } \\
\text { and Maculopathy, } N=395\end{array}$ & Frequency & $\begin{array}{c}\text { Percentage } \\
(\%)\end{array}$ \\
\hline Retinopathy & & \\
\hline No Retinopathy & 334 & 84.6 \\
\hline Mild \& moderate Retinopathy & 54 & 13.7 \\
\hline Proliferative & 7 & 1.8 \\
\hline \multicolumn{3}{|l|}{ Maculopathy } \\
\hline No Maculopathy & 368 & 93.2 \\
\hline Maculopathy & 27 & 6.8 \\
\hline
\end{tabular}

\section{DISCUSSION}

The prevalence of any diabetic retinopathy was $15.5 \%$. This has not changed much in nearly a decade and a half since 2003 when a similar study conducted in the same area by Rotimi et al found a prevalence of $17.9 \%{ }^{5}$ This is lower than the estimated global prevalence of $34.6 \%$ for all retinopathy. ${ }^{3}$ But within the ranges of the prevalence of any retinopathy of 7-62.4\% ${ }^{4}$ for clinic-based studies in Africa and population-based studies of any retinopathy of $9.2 \%^{8}, 37.5 \%^{8}, 15 \%^{10}$ and $23 \% .^{11}$

The prevalence of proliferative retinopathy of $1.8 \%$ in this study is much lower than the global proliferative diabetic retinopathy prevalence of $6.9 \%{ }^{3}$
However, the prevalence of proliferative retinopathy demonstrated by this study compares similarly with the prevalence of 0-6.9\% for clinic-based studies in Africa. ${ }^{4}$ In this study, the prevalence of legal blindness was $5.8 \%$ and of all visual impairment was $12.6 \%$. More than half $(59.1 \%)$ of participants had not had an eyes evaluation ever since they were diagnosed with diabetes mellitus. This was higher than in Ethiopia where 42.9\% of diabetics had been screened for Diabetes retinopathy. ${ }^{12}$

This represents a significant number of diabetics who are not getting an eye evaluation thus increasing their risk for losing their vision. About a quarter $(24.0 \%)$ of the eyes examined had cataracts. This value is higher than that found in an African study by Eugene Sobngwi and colleagues (14.38\%). ${ }^{9}$ It is lower than that found by Mash and colleagues in their study (35.2\%). ${ }^{13}$ It is lower than a study in the same study area by Rotimi et al . ${ }^{5}$

They found that $40 \%$ of diabetics had visually impairing cataract ${ }^{5}$. This seems to suggest that there has been a reduction of $42 \%$ in 10 years in the prevalence of visually impairing cataracts amongst diabetics in the same area. Over this period the cataract surgical rate in Ghana has improved from 300 to 900 . This could explain the reduced prevalence of cataract amongst diabetics. It may also be an indication of better sugar control in diabetics in the study area.

The limitations of this study are that since it is a hospital-based study the results cannot be applied to the general population. The fact that the retinal findings were not cross checked by another retinal specialist may also lead to under and over diagnosis of retinopathy. Ocular coherence tomography (OCT) was not used to evaluate the maculopathy in this study, as it was not available in the study area at the time of the study. As such the assessment of maculopathy was only based on qualitative clinical judgement.

\section{CONCLUSION}

In the hospital setting of this region of Ghana, $18.4 \%$ of all diabetics attending the clinic have impaired vision of which $5.8 \%$ are legally blind. More than half (59.1\%) have not been screened for diabetic retinopathy. Since diabetics are already a very debilitating disease, any further visual disabilities in addition to the numerous other disabilities greatly reduce the quality of life and life expectancy. There is an urgent need to have an effective screening program to prevent diabetics from losing their vision and getting blind 


\section{REFERENCES}

1. Godfrey R, Julien M. Urbanisation and health. Clin Med. 2005; 5:137-141.

2. Shaw JE, Sicree RA, Zimmet P Z. Global estimates of the prevalence of diabetes for 2010 and 2030. Diabetes Res Clin Pract. 2010; 87(1) :4-14.

3. Yau JW, Rogers SL, Kawasaki R, Lamoureus EL, Kowalski JL ,Bek T et al. Global prevalence and major risk factors of diabetic retinopathy. Diabetes Care. 2012; 35(3): 556-564.

4. Burgess PI, MacCormick IJ, Harding SP, Bastawrous A, Beare NE, Garner P. Epidemiology of diabetic retinopathy and maculopathy in Africa: a systematic review. Diabet Med. 2013; Apr, 30 (4) : 399-412. doi:10.1111/j.1464-5491.2012.03756.x.

5. Rotimi C, Daniel H, Zhou J, Obisesan A, Chen G, Amoah A et al. Prevalence and determinants of diabetic retinopathy and cataracts in West African type 2 diabetes patients. Ethn Dis. 2003; (2 suppl 2):S110-117.

6. Danquah I, Bedu-Addo G, Terpe K, Micah F, Amoako YA, Awuku YA. Diabetes mellitus type 2 in urban Ghana: characteristics and associated factors. BMC Public Health .2012 Mar 20 ; (12) 210: doi: 10.1186/1471-2458-12-210

7. Amoah AG, Owusu SK, Schuster DP, Osei K. Pathogenic mechanism of type 2 diabetes in Ghanaians--the importance of beta cell secretion, insu- lin sensitivity and glucose effectiveness. S. Afr. Med. J. 2002 May; 92(5): 377-384.

8. Mengesha AY, Spectrum of eye disorders among diabetes mellitus patients in Gaborone, Botswana. Trop Doct .2006 Apr; 36(2): 109-111.

9. Sobngwi E, Mbanya JC, Moukouri EN, Ngu KB . Microalbuminuria and retinopathy in a diabetic population of Cameroon. Diabetes Res. Clin. Pract. 1999 Jun; 44(3):191-196.

10. Omolase CO, Adekanle O, Owoeye JF, Omolase BO. Diabetic retinopathy in a Nigerian community. Singapore Med J. 2010 Jan; 51(1): 56-59.

11. Unuigbe EI, Omeife H, Edema T, Ukoli FA. Microalbuminuria and associated factors in newly diagnosed diabetics. Niger Postgrad Med J .2001 Dec; 8(4):187-192.

12. Gudina EK, Amade ST, Tesfamichael FA, Ram R - Assessment of quality of care given to diabetic patients at Jimma University Specialized Hospital diabetes follow-up clinic, Jimma, Ethiopia. $B M C$ Endocr Disord 2011 11, 19. doi: 10.1186/14726823-11-19.

13. Mash B, Powell D, du Plassis F, van Vuuren U, Michalowska M, Levitt N . Screening for diabetic retinopathy in primary care with a mobile fundal camera--evaluation of a South African pilot project. S. Afr. Med. J. 2007; 97(12):1284-1288. 